Available online at www.jmle.org

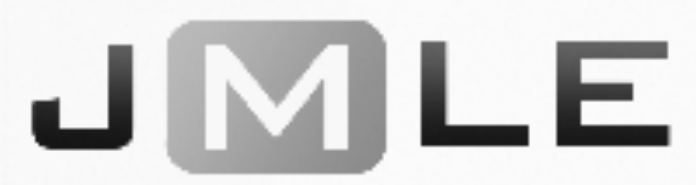

The National Association for Media Literacy Education's

Journal of Media Literacy Education 10 (2), 123 - 138

\title{
Both Facts and Feelings: Emotion and News Literacy
}

\author{
Susan Currie Sivek \\ Linfield College
}

\begin{abstract}
News literacy education has long focused on the significance of facts, sourcing, and verifiability. While these are critical aspects of news, rapidly developing emotion analytics technologies intended to respond to and even alter digital news audiences' emotions also demand that we pay greater attention to the role of emotion in news consumption. This essay explores the role of emotion in the "fake news" phenomenon and the implementation of emotion analytics tools in news distribution. I examine the function of emotion in news consumption and the status of emotion within existing news literacy training programs. Finally, I offer suggestions for addressing emotional responses to news with students, including both mindfulness techniques and psychological research on thinking processes.
\end{abstract}

Keywords: news literacy, emotion analytics, mindfulness, misinformation, cognition

Reporter Katie Notopoulos of BuzzFeed News (2018) wrote recently about a Facebook post she shared that persisted in her friends' news feeds for days. The seemingly innocuous home decor video received a few comments:

And then people commented on the comments. The more people commented, the more the video showed up on other people's feeds. As the rage around this post intensified, so did the comments. Coworkers I sit next to commented. College friends commented. Someone I went to preschool with commented. A vicious, algorithmically delicious cycle.

Notopoulos' editor saw the post and the string of interactions it wrought, and asked her to write about how it reflected Facebook's new algorithmic effort to "prioritize posts that spark conversations and meaningful interactions between people" (Mosseri, 2018).

But which conversations and interactions are meaningful? And what if the original post contains inaccurate, deliberately misleading, and emotion-laden content, targeted to entice users into engagement and designed to be "algorithmically delicious"? 
The digital proliferation of what many call "fake news" is coinciding with ever more sophisticated efforts to target users. What is less well known is the degree to which emotions are a focus of this personalization, and how feelings may be manipulated with new emotion analytics tools that assess and respond to users' emotional states. Today, two-thirds of Americans get news from social media (Shearer \& Gottfried, 2017). As emotion becomes increasingly fundamental to efforts to spread digital content - including false and provocative political memes and stories it is critical that news literacy education more strongly emphasize critical thinking about the feelings generated by news, not just about the facts provided within it.

In this essay, I address the role of targeted, emotion-focused content in today's digital environment, and offer perspectives from psychological research on the role of emotion in judgments and decision-making. I also explore how emotional skills are, and may be further, addressed in news literacy instruction. I provide two concepts with which instructors can expand instruction in emotional skills related to news consumption, as well as practical activities to bring each concept into the classroom.

\section{VARIETIES OF NEWS IN THE DIGITAL ATTENTION ECONOMY}

Today's news media operate within an attention economy wherein it is critical to capture the minds and emotions of audiences within a fraction of a second - a high-speed maneuver outpacing journalism of the past. Alongside traditional normative criteria, web and social media analytics also drive editorial decisions, as news must compete for attention among funny memes and enticing food videos. This mix of content resides within a carefully constructed, algorithmically generated environment that aims to retain our attention as long as possible. As Eyal (2014) details, online platforms work hard to "manufacture" our habits, to play upon our routines and feelings to keep us coming back daily, if not hourly, for another dose (p. 3). That compulsive use of digital media is fantastic for revenue generation. After all, as users peruse websites and apps, they are also exposed to advertising and sponsored content. Facebook, Twitter, Google, and most digital publishers rake in billions of dollars from advertising revenue thanks to users' willingness to view and click on advertising.

Content distributed on social media platforms has presented special challenges because these platforms have accepted little responsibility for the content itself. All of these platforms have faced controversy regarding hateful and/or violent content. Their responses have been slow and inadequate. For example, after largely permitting harassment and racist speech on its platform for years, Twitter only recently started enforcing stricter policies regarding hateful imagery and speech, abusive interactions, incitement to violence, and other problematic content (Lee, 2017).

Perhaps more difficult for these platforms to discern - but no less problematic - is what has widely been labeled "fake news." A reliable definition of "fake news" is difficult to formulate, and may even vary based on the individual audience member's own ideological proclivities. The term "fake news" could refer to content produced with ethical intentions and distributed by reputable news organizations, but that inadvertently contains inaccurate information due to a simple error. The term could also refer to blatantly false, deliberately misleading, ideologically based content designed to manipulate audiences' reactions and perspectives. There is a range of possibilities in between. To be sure, different kinds of news content may demonstrate varying degrees of accuracy/falsehood and ethical/manipulative intention, and diverse audience members may perceive these facets of content differently. However, in order to proceed with discussion of these issues, I will consider "fake news" for this argument to include primarily the types of content 
that would fall into the lower right quadrant of Figure 1. Figure 1 illustrates one possible configuration of these relevant characteristics and offers spectra, not strict classifications, upon which different content might be located, recognizing the malleability and subjectivity of these attributes.

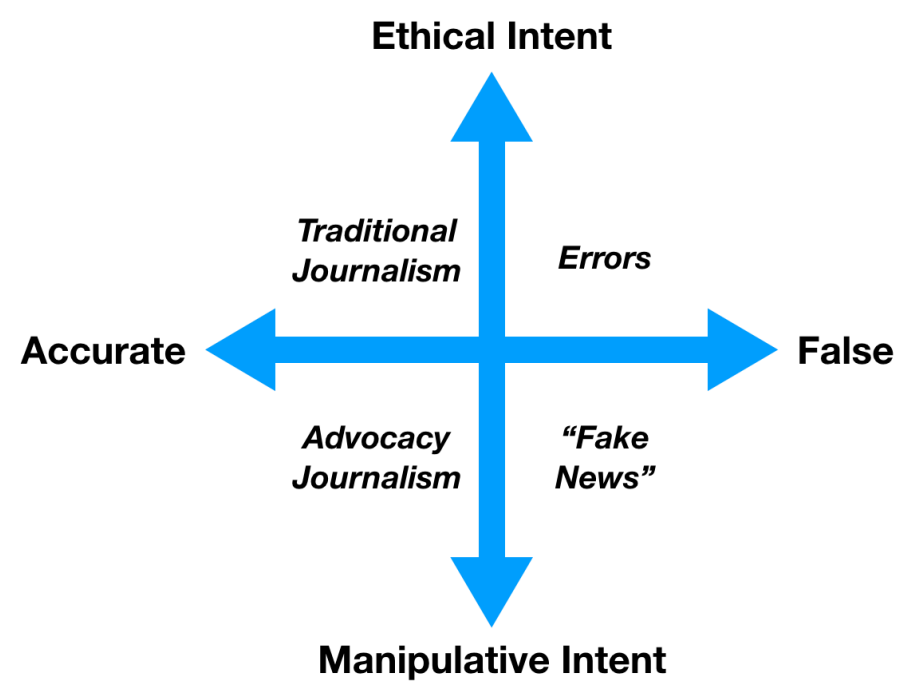

Figure 1. Key attributes toward a definition of "fake news"

I here use the term "fake news" to encompass manipulative, knowingly and purposefully inaccurate, news-like stories and images that are designed to appeal to users' ideological stance, their emotions, and their desire to spread their perspective to others. For my purposes, this content is distinctive from other persuasive media (e.g., advertising) in that it specifically co-opts tropes and norms of journalism for the purposes of manipulation. Furthermore, it differs from "yellow journalism" in that yellow journalism as a term typically refers to sensationalized, exaggerated news that is at least partly based on accurate information - i.e., perhaps falling somewhere near the center of Figure 1 - while "fake news" may be entirely fabricated.

In contrast, legitimate, reliable news sources - e.g., newspapers of record like the New York Times or Wall Street Journal, or fact-checked publications like The Economist - adhere to widely accepted principles and practices within the journalism profession, and are publicly acknowledged as information sources of value. They enact principles and practices like those included in the Society of Professional Journalists' Code of Ethics, which describes journalists' aspiration for "public enlightenment" through "the free exchange of information that is accurate, fair and thorough" in varied media (SPJ, 2014). Journalists abiding by this code are enjoined to "seek truth and report it" and to "label advocacy and commentary" (SPJ, 2014).

Admittedly, these long-lived, well-established, "mainstream" news organizations make factual and ethical errors, both big and small, in their work on occasion. Some critics may also argue - with good reason - that these organizations' selection and presentation of news is inherently biased due to the influence of their corporate owners, their profit motive, trends in media consolidation, their advertisers' interests, and other economic factors (e.g., McChesney, 2015). Therefore, it is perhaps best to evaluate "legitimate" versus "fake" news as a matter of not only veracity but also intent, as shown in Figure 1: whether the creator and/or distributor of the 
news aims largely to enhance "public enlightenment" or for (mis)direction toward other goals. Content may purport and appear to be factual journalism, but truly has primarily a manipulative intent and may deviate from factual accuracy to achieve that goal.

This misleading, inaccurate content is the "fake news" that is of most concern to critics today and is the focus of this essay. Having this kind of content widely available online presents a significant additional risk to accurate public understanding of events and issues, and generates distrust in legitimate, reliable news sources. Marwick and Lewis (2017) thoroughly describe the motives of and the manipulative strategies used by those who create different styles of this content, which are beyond the scope of this essay but useful to understand. As these authors point out, declining public trust in news media and the reliance of news media companies on social media platforms both have contributed to the public's acceptance of fake news and their willingness to spread it. Moreover, fake news itself often becomes the topic of coverage. As public interest in a fake and viral story rises, journalists are driven to address it: either to fact-check and debunk it, or to create their own click-generating content with proven appeal to audiences.

\section{Emotion Analytics: Refining the Emotional Appeal of Fake News}

Fake news presents an emotionally resonant alternative to valid information, threatening audiences' opportunity to become informed citizens and their participation in a functional democracy. Unlike the objective tone sought by most mainstream journalists, creators of fake news typically seek to strike an emotional chord that will spur audiences to react and to share the fake content. This strongly emotional framing of much fake news probably aids its spread. Research suggests that news content and other imagery that generates strong emotion is more likely to be shared; negative emotions seem to increase the likelihood of virality (Jones, Libert, \& Tynski, 2016). One analysis found that, in the three months before the 2016 U.S. presidential election, the highest-performing fake (completely false) news on Facebook actually generated more user interaction (reactions, comments, shares, etc.) than did the highest-performing legitimate news stories from real outlets. All of the fake news stories in that analysis came from sites publishing solely hoaxes or from hyperpartisan sites that mimicked real news (Silverman, 2016). Users were either deceived by the content and found it provocative enough to engage with it - or they knew it was deceptive and were still willing to share it, perhaps to recruit others to their own partisan perspective or just to get a reaction from friends.

Although fake news creators (as profiled by Marwick and Lewis, 2017) are already effectively spreading their content, their efficacy may increase as emotion analytics tools are more widely implemented among digital publishers and platforms. Emotion analytics includes a range of software and hardware designed to detect, identify, and respond to users' emotional states (catalogued well by Yonck, 2017). These tools developed in the field of affective computing, which originally aspired to improve humans' interactions with computers (Picard, 2000). For example, if you were becoming observably frustrated with software, the computer could respond with tips to reduce your annoyance. Initial affective computing applications included tools like emotion analysis devices for children with autism, which used facial recognition to help them identify and respond to others' emotional states (El Kaliouby, Picard, \& Baron-Cohen, 2006).

However, as with many technologies, developers soon saw greater profit potential in applications beyond the altruistic. Technology companies like Affectiva (2018) have created market research and media testing methods that assess test subjects' emotions as they view product designs, ad campaigns, or TV content. Additionally, beyond the lab, methods for detecting data related to emotion have now been integrated into many devices we use daily. Smartphones collect 
data on app usage, location, media choices, physical activity, and even the pressure with which we touch the screen. Smart watches and wearable devices monitor our heart rates and movement levels. Social media platforms and messaging tools collect text and imagery we voluntarily contribute, as well as our emotional "reactions" to others' content, made more precise through emoji selection. Voice-activated home assistants (e.g., Amazon's Echo) can assess vocal tone and speech content. Cameras in homes, workplaces, and public settings, as well as on our devices, can examine our facial expressions to assess our current feelings. All of these data sources can be combined to establish an emotional baseline and to determine a user's emotional state at any given moment and respond accordingly (Sivek, 2018b).

Emotional analysis of individual users in real time may sound far-fetched, but Apple and others have already patented techniques for gathering, compiling, and analyzing these expressions of emotion (e.g., Greenzeiger, Phulari, \& Sangavi, 2015). Their intended response would be - of course - to provide media content and advertising befitting users' emotional states. As one Apple patent states, the goal is to avoid "periods of time where the targeted content delivery is misaligned, thereby resulting in decreased satisfaction for both the content provider and the content receiver" (Greenzeiger et al., 2015). Whether users' emotional state is positive or negative, the goal is to market to them more effectively, not to improve well-being (though, to be fair, there are also some mental health and wellness applications in development that use emotion analytics).

\section{MANIPULATION OF EMOTION WITH PERSONALIZED (FAKE) NEWS}

Accessing, monitoring, and potentially manipulating people's emotional status through technology should raise numerous ethical and legal issues. Sedenberg and Chuang (2017) provide a thorough overview of these concerns. I will focus here on the potential uses of emotion analytics in conjunction with fake news and media manipulation; this (mis)use fits what Sedenberg and Chuang term "harms [from] invisibly adapting advertising or customization" (p. 10). As I have addressed in depth elsewhere (Sivek, 2018a), truthful, legitimate news from reputable news organizations may also be shaped and distributed with the help of emotion analytics. Yet the algorithmic selection of fake news poses additional risks beyond the widely discussed concerns about "filter bubble" or "echo chamber" phenomena (Pariser, 2011), and has not received broader attention.

Certainly, emotion analytics could benefit individuals' news consumption by providing stories when audiences are prepared to consume them thoughtfully. For example, I would prefer not to receive potentially upsetting news alerts on my phone early in the morning or after about 9 p.m. at night - times when I am striving for equanimity. However, an alert for a useful service story or an enjoyable human-interest story might be welcome. Emotion analytics could also be used to identify and even restrict the spread of emotionally charged and inaccurate news on social media, though what might be "restricted" would be difficult to define. (Of course, even these more "positive" applications still imply the regulation and selection of our news and information by privately owned digital media companies, a concern in itself.)

However, trends in the customization of information delivery with user data suggest a more worrisome scenario. Consider, for example, the use of "engagement scripts" by companies like Cambridge Analytica, now (in)famous for its personalization of social media content during the 2016 U.S. presidential election. Cambridge Analytica has since folded, but some of its employees now work for a new company called Data Propria, which has already begun work on the 2020 Donald Trump campaign (Robertson, 2018.) Drawing on a repository of thousands of versions of 
Trump campaign ads, Cambridge Analytica precisely targeted ads to individual users. Targeting was based on personality profiles formed from individual users' online activities. The company's CEO claims it has "more than 5,000 data points on every voter in the United States" (Nix, 2016).

Using these data, Cambridge Analytica generated customized ad campaigns for each user, essentially running constant A/B tests to tailor ads' themes and content for individual personality profiles (Anderson, 2017). Moreover, there was a "synergy" between these ads and fake news, as users' engagement with fake news further refined the targeting:

The more fake news that users engage with, the more addictive Analytica's personality engagement algorithms can become. Voter 35423 clicked on a fake story about Hillary's sex-trafficking ring? Let's get her to engage with more stories about Hillary's supposed history of murder and sex trafficking. (Anderson, 2017)

It is plausible that the same effect occurred with emotionally provocative memes and images shared by Russian operatives on social media; interactions with the politically charged content brought users more of the same (Parlapiano \& Lee, 2018; Tiku, 2017).

Now, envision the addition of real-time emotion data to this already incredible user targeting. Tufekci (2015) points out that this is "something advertisers have always tried to do, but never were able to carry out ... targeting people specifically, and privately, through their vulnerabilities" (p. 212). Users could be provided precisely the right fake news story or ad not only to suit their personality type and preferences, but also to respond to their emotional status at that moment. Are your devices suggesting you're agitated, frustrated, and tired at the end of your workday, as assessed through your heart rate, respiration rate, facial expressions, time of day, and pressure applied on touch interfaces? Sounds like a great time for a distracting fake news story that plays into your anger toward a particular political candidate or your frustration with a specific policy. You probably won't be too critical or have time and energy to fact-check, and sharing the "news" with friends could offer catharsis for the general sense of annoyance felt after a long, difficult day.

This scenario is a hypothetical pairing of an emotional state to one kind of emotional framing of a news story. Other kinds of pairings could be more effective - an inspirational story at the end of a tough day? Whatever the magic combination, data analytics companies have both the capacity to find it and the clients who want to profit from it. Unfortunately, if not used in conjunction with strict ethical guidelines or governmental regulation, it seems probable that audiences' emotional states will be considered just another form of data to be used in message targeting, using whatever legitimate or fake content a customer wants to pay to distribute.

\section{News, Emotion, and the Affect Heuristic}

The intersection of emotion data and news becomes even trickier in light of research on the role of emotions in decision-making. As Slovic et al. (2007) describe, people use an "affect heuristic" to form preferences: "In the process of making a judgment or decision, people consult or refer to an 'affect pool' containing all the positive and negative tags consciously or unconsciously associated with the representations" (p. 1335). These associations form through a lifetime of learning about the world both directly and via media messages, during which conditioning connects positive and negative feelings to experiences (p. 1335). Those feelings are critical to navigating the world. Emotion is thereby "a strong conditioner of preference" (Slovic et al., 2007, 
1336). We need to place information into "an affective frame of reference" that combines facts with emotion so we can form preferences and make decisions (Slovic et al., 2007, p. 1340).

The shaping of decisions through emotion operates even with very brief exposures to emotional content, as short as 1/250 of a second, "an interval so brief that there is no recognition or recall of the stimulus" (Slovic et al., 2007, p. 1336). It would seem that even scrolling quickly through social media feeds laden with emotionally provocative content could contribute to a user's affective conditioning regarding news stories and newsmakers, thereby altering over time the user's judgments of them. Representations of emotion, whether words or images, may only be subliminally perceived during such scrolling, yet still affect audiences' evaluation of information (Dehaene, 2014, p. 69). Additionally, time pressure - inherent to social media, where scoops and timeliness rule - also has been shown to "reduce the opportunity for analytic deliberation ... allowing affective considerations freer rein" (Slovic et al., 2007, p. 1344). Finally, "vivid, affectladen" images and scenarios (anecdotes and narratives) also play upon the affect heuristic, causing audiences to inaccurately assess frequencies of harm and risk (e.g., of violence; Slovic et al., 2007, p. 1345). Fake news often uses vivid imagery and dramatized scenarios to provoke viewers' interest and emotion.

In short, the distribution of emotionally framed news on social media invokes audiences' affect heuristic, with emotion perhaps shaping their analyses of people and issues more strongly than can their analytical capabilities. As Slovic et al.'s synthesis of research (2007) on the affect heuristic points out:

Manipulation of attitudes and behavior by persuasive argumentation is often quite effective, but at least it tends to be recognized as an attempt to persuade. Manipulation of affect is no less powerful but is made more insidious by often taking place without our awareness. (p. 1348)

Fake news creators' desire to manipulate users' emotions, combined with emerging tools for recognizing and responding to users' emotions through their personal data, should together cause considerable concern. Some research already suggests that "morally framed emotional expressions" are more likely to be shared on social media, and that political actors could productively take advantage of this user tendency (Brady et al., 2017). Research on the affect heuristic demonstrates how emotions are essential factors in humans' decision-making. As much as we might like to think it, we aren't solely analytical creatures. Our emotional capacities appear freshly vulnerable to external influence in this new technological context.

\section{Emotion in Today's News Literacy Education}

Absent sudden governmental interest in the regulation of personal data, our emotions will increasingly be targeted to shape our preferences and decisions. Yet most news literacy education has focused on responding to factual issues and the "attempts to persuade" that Slovic mentions, which generally carry more visible markers - questionable URLs, clickbait-style headlines, biased language and imagery, and/or missing sources.

"News literacy" is arguably a more specific application of "media literacy," which itself can be defined as "the ability to encode and decode the symbols transmitted via media and the ability to synthesize, analyze and produce mediated messages" (NAMLE, n.d.). Narrowing this conception of media literacy, Fleming (2015) offers that news literacy is the "ability to access, evaluate, analyze and appreciate journalism" (p. 76). Maksl, Ashley, and Craft (2015) describe 
news literacy as "knowledge and motivations needed to identify and engage with journalism" (p. 29). Reese (2012) requires 'the ability to understand, 'decode,' and create media with particular awareness of one's social location within an international context" (p. 65).

These definitions focus on the cognitive aspects of news literacy: the ability to locate news and evaluate its factual content. Formal news literacy curricula do not often address the role of emotion in depth. For example, the News Literacy Project's Checkology checklist offers 17 questions for the assessment of news stories. Notably, this checklist encourages users to think first about emotions elicited by stories, prior to evaluating other story characteristics (Caulfield, 2017; Checkology, n.d.). Yet the checklist offers little guidance for handling that emotion. Instead, strong emotions are merely deemed "red flags," equivalent in the checklist to a story's excessive punctuation or missing byline.

Even in the Stony Brook news literacy course, one of the most comprehensive collegelevel news literacy efforts, Fleming (2015) found within the instruction minimal discussion of emotional aspects of news literacy. She reported that most of the existing discussion occurred within an autobiographical context, often drawn from instructors' professional journalism experiences (Fleming, 2015, p. 82) - as opposed to instruction on how to identify and contend with the emotional context and content of news.

A Stony Brook news literacy tool titled "Taxonomy of Information Neighborhoods" is also somewhat confusing in its guidance about emotion. It states that an information type labeled "propaganda" will use "emotional manipulation through images" (Klurfeld \& Schneider, 2014, p. 10). However, legitimate journalists use emotional imagery and narratives often to help audiences understand the significance of news topics. Can students discern the difference between what is here labeled "propaganda" and the use of an emotionally charged image in legitimate photojournalism? Is an emotionally powerful image of a natural disaster "propaganda," according to this definition? Can students understand when their emotions are being fairly invoked - or misleadingly targeted? And what about emotional manipulation that is unseen, as in the application of many emotion analytics tools described earlier in this essay?

The current focus on the cognition around news neglects the critical component of affect in evaluation and decision-making. There is a broader trend in education to develop students' emotional skills (Zernike, 2016), sometimes even using emotion analytics tools (Spreeuwenberg, 2017; Williamson, 2017, offers a thoughtful critique of this technological approach). Teaching greater emotional awareness as a component of news literacy could support this broader effort. However, given trends in the information environment, enhancing news literacy instruction with a stronger focus on emotion's role is an important step.

\section{BRINGING EMOTION INTO NEWS LITERACY INSTRUCTION}

As Potter (2013) mentions, individuals' general emotional development is a key part of media literacy (pp. 23-24). However, as this essay has attempted to establish, today's constant appeal to emotion in news and digital media means that emotional skills are critical accompaniments to cognitive skills in news literacy. What would instruction in these skills look like in practice?

Two particular areas of research and practice may be helpful in guiding students to understand the role of their emotions in their awareness of, responses to, and evaluation of news. First, trendy yet timeless mindfulness techniques would aid students in recognizing when and how they respond emotionally to news. Second, Kahneman (2011) provides a neatly constructed 
framework of two modes of thinking, labeled "System 1" and "System 2," that are easily understood and could be taught in the context of news literacy, especially in conjunction with insights into the affect heuristic.

\section{Mindfulness in News Literacy: Concepts and Activities}

A striking finding of one study of the Stony Brook news literacy program was that its student participants found they were constantly exposed to large quantities of news. However, they only recognized that exposure upon reflection, and they realized they had not been processing that news consciously (Klurfeld \& Schneider, 2014, p. 8). Emotional and cognitive responses undoubtedly occurred all the time without the students' awareness.

A valuable first step in advancing news literacy would be to aid students in mindfully understanding when, where, and how they are exposed to news, and to encourage more deliberate attention to and processing of news. While "mindfulness" may be a fashionable buzzword today, it is a long-held tenet of Buddhist tradition, dating back to the teaching of the Buddha in the fifth century B.C.E. (Bodhi, 2013). In the late 1970s, mindfulness practices migrated to the West, partly through the work of Jon Kabat-Zinn, who developed a now-common therapeutic technique called Mindfulness-Based Stress Reduction (MBSR). Bodhi (2013) suggests that mindfulness "involves the reflexive contemplation of one's own experience ... the body, feelings, states of mind, and experiential phenomena ... [with] lucid awareness" (pp. 21-22).

Psychological research has suggested that people who are more mindful may experience fewer "cognitive failures," such as forgetfulness, distractibility, mistakes, and other kinds of mental "blunders" (Herndon, 2008). Moreover, people who are more mindful may be more open to information from the external world, helping them be less prone to "self-perpetuation errors," in which they continue to believe in their own inaccurate conclusions despite external evidence to the contrary (Herndon, 2008). There is some support for the positive impact of mindfulness training on critical thinking skills (Noone, Bunting, \& Hogan, 2016). Training in mindfulness techniques also helps people recognize affective "cues" more quickly and initiate regulation of their emotions immediately, if necessary. As Teper, Segal, and Inzlicht (2013) write, mindfulness "promotes an openness and sensitivity to subtle changes in affective states, which are essential in signaling the need for control and in energizing its execution" (p. 449). Mindfulness training also enhances areas of the brain that "pull together thought and feeling" during reading, thereby better equipping them to understand varying human perspectives (Wolf, 2016, pp. 115-116). Overall, mindfulness skills appear to have promise as a means of increasing news consumers' awareness of their emotions and reducing their "cognitive failures" regarding the information they see.

In some primarily Buddhist regions, the goal of "lucid awareness" of exposure and response to media has been institutionalized in media literacy education. Some Thai media literacy educators have implemented mindfulness principles in their instruction, seeking to develop "media wisdom" in their students (Kleebpung, 2017, p. 51). For example, Ratanangam created a program encouraging "a mindful and conscious approach for 'patient perception' of the media" (as cited in Kleebpung, 2017, p. 51). Furthermore, according to Kleebpung (2017), the media literacy curriculum created by the Thai Civic Education agency has focused on "the direct experiences of how media evoke personal feelings and emotions" (p. 51). This approach to training students in awareness of their news consumption and subjective responses - not just facts and sources may prove prescient in this time of emotionally provocative (fake) news content. As Malikhao (2017) indicates, "mindful communication" by all media producers and users would diminish the spread of fake news, hoaxes, and clickbait. 
A full review of the many ways mindfulness has already been incorporated into general educational efforts is beyond the scope of this essay. However, there are many ways that teachers have brought mindfulness principles and practices into both K-12 (Felver et al., 2015) and college (Barbezat \& Bush, 2013) classrooms. With regard to media and news literacy education specifically, assignments and exercises could encourage students' awareness of news exposure and of their emotional responses to it, thereby encouraging further analysis of emotions spurred by provocative real or fake news content (and, ideally, discouraging the spread of the latter).

First, as mentioned above, Stony Brook students noted that they often were not aware they were exposed to so much news (Klurfeld \& Schneider, 2014, p. 8). Therefore, an excellent first task that would aid students at any age is relatively simple: logging news exposure. Students can note when they encounter news through various media, whether a push notification on a phone, a newspaper on a bus seat, or a story on a TV in the gym. Simply gaining that "lucid awareness" of news's presence is progress toward understanding one's reactions and feelings.

Such a log could include a quick note of how the student felt upon seeing each news item. Many people have observed the amplified stress caused by seeing constant news notifications on their phones, for example. Even a simple (and fun) selection of an emoji to represent the student's immediate emotional response to the news exposure could provide insights into the patterns of feelings caused by different news stories and/or delivery mechanisms. Students may wish to adjust their news usage or reconsider their desired actions with the news item (e.g., sharing it or factchecking it more carefully) after evaluating the emotional response.

Additionally, perhaps after a news log activity, students can experiment with deliberately scheduling news consumption from specific sources and strategically limiting their overall exposure, while still gathering necessary information to stay current. A regimen of intentional news consumption can be much more emotionally manageable in that it limits the challenging feelings caused by many news stories to a defined time period. This regimen likely also would encourage consumption from more moderately framed sources. A student who obtains news in a scattershot fashion throughout the day from various social media posts is assuredly going to skim past valuable information (but still be emotionally affected by it), to encounter emotionally framed "news" content, and to fall victim to friends' sharing of provocative but inaccurate information. In contrast, a student who intentionally visits a few major news websites via their home pages, once or twice each day, is probably going to see more thoughtfully presented, professionally vetted, less sensational news that does not seek to engender such dramatic emotional responses.

Having students experiment with and reflect upon different means of engaging with news sources may reveal the emotional roller coaster that is social media-driven, emotion analyticstargeted news consumption. Students may choose to alter their strategies for gathering news. In addition to these suggestions for engaging news more mindfully, Zomorodi (2017) offers an accessible, entertaining set of practical exercises, supported by expert commentary, that students and others can use to assess, experiment with, and reshape news and other digital media habits.

\section{Affect and News Literacy: Concepts and Activities}

Beyond encouraging greater awareness and emotional savvy with regard to news, instructors might also consider teaching students basic principles from the research on the role of emotion in decision-making and preference formation. As Slovic et al. (2007) establish, affect is inseparable from our ability to comprehend and evaluate information:

the affect heuristic ... appears at once wondrous and frightening: wondrous in its speed, and subtlety, and sophistication, and its ability to 'lubricate reason'; frightening in its 
dependency upon context and experience, allowing us to be led astray or manipulated inadvertently or intentionally - silently and invisibly. (p. 1349)

In the context of news and digital media, as this essay has discussed, "intentional" efforts to play upon our emotions for political gain and/or profit have escalated. Therefore, though perfect awareness may be impossible, we must strive to be at least somewhat more conscious of how emotions sway us and how our emotional responses to people and ideas have been conditioned over time.

While the affect heuristic sounds obscure and complex, it is in fact readily illustrated using everyday experiences. For example, Hsee (1998) offers an example of consumers' evaluation of two ice cream choices: a big, underfilled cup, or a small, overfilled cup. The big cup actually contained more ice cream, yet the small cup was valued more highly by consumers, as measured by how much they said they'd pay for it. This brief, relatable example shows how our emotions guide our perceptions and determination of value. The experimental psychology literature yields a wealth of examples of the influence of affective (emotional) judgments on decisions - whether personal and minor, or political and consequential. These examples could be used with students to initiate discussion of other contexts in which emotion hinders rational evaluation.

A further exercise to guide students' consideration of the role of emotion in news could focus on how narrative provokes audience emotion. As discussed earlier, creators of news-like texts often use emotionally stirring anecdotes, scenarios, and images to interest audiences and convey the importance of issues and events. Analyzing these emotional presentations with students might include talking about how this emotional provocation was constructed, how it affected them, and whether and how it might have changed their thinking about the larger topic of a story. A further step in this analysis could be to ask about the specific selection of narrative or image. Why use this narrative and this image to illustrate this point and to make audiences feel a certain way? How would the story and our reactions differ if another narrative or image had been selected? This approach is somewhat similar to a strategy employed by Perry et al. (2017), who demonstrated effective development of students' critical thinking skills through the analysis of "competing narratives" about climate change.

Another worthwhile approach to this issue from a psychological perspective is presented in the work of Kahneman (2011), whose bestselling book Thinking, Fast and Slow offers an excellent framework that can be shared with students of just about any age. Kahneman's book synthesizes many studies to present the idea that we have two "systems" - 1 and 2 - that guide our everyday thinking. System 1 guides involuntary, fast, and automatic activities and decisions; System 2 engages in complex thinking and concentrated work, requiring effort and focus (Kahneman, 2011, p. 21). System 1 causes much of the behavior we consider problematic with regard to the consumption and spread of fake news, hoaxes, and other misinformation. System 1 "generates impressions, feelings, and inclinations ... neglects ambiguity and suppresses doubt ... is biased to believe and confirm ... [and] focuses on existing evidence and ignores absent evidence" (Kahneman, 2011, p. 105). Kahneman's framework is relatively easy to explain with the help of the many examples he provides. Various talks and demonstrations are available as online videos to assist in the classroom. Some educational programs that emphasize deliberate, "slower" thinking over automatic responses have demonstrated improved academic and interpersonal outcomes for students (e.g., Algan et al., 2014; Heller et al., 2017). These strategies also may reinforce broader efforts to teach "critical thinking," in all of its forms, at various educational levels.

Ideally, guiding students through an explanation of these varying thinking processes would help them gain insight into how they form opinions and reach decisions on a whole range of issues, 
including their interactions with news and information. A focus on the role of emotion in these processes would highlight how news content designed to manipulate our feelings can result in different evaluations and, therefore, produce different attitudes and actions. It is impossible for us to consciously and fully identify in real time the operation of our own mental processes, but it is certainly a positive goal to seek some awareness of how and why we form opinions or take particular actions. When we see emotionally provocative news content and realize that emotional manipulation may be occurring, we can attempt to short-circuit that process and engage that information in a more cognizant manner. If nothing else, encouraging students to briefly "pause" their thinking and reactions as they consume news content - and decide whether to spread it further - will surely be beneficial.

\section{THE BIGGER PICTURE: SOCIETAL AND POLICY ISSUES}

In addition to introducing students to these concepts, instructors can enhance students' news literacy in today's troubled information environment by addressing larger societal issues and policy approaches related to emotion in news and digital media.

Informing students about the role of emotion in the design and spread of fake news and hoaxes is valuable, as is educating them about the increasing significance of emotion data and analytics for digital media publishers and other technology companies. Beyond now-familiar discussions about digital privacy that educators have led for decades, students should be aware that devices they use and wear are also gathering data that analyze their emotions, as are devices they may or may not perceive in public and private spaces, such as digital home assistants and surveillance cameras. This form of data gathering has received little public attention as of yet.

Emotion analytics tools can be difficult to evade, given their growing integration into many devices and environments. For example, Sedenberg and Chuang (2017) discuss the evolving social norms around taking, sharing, and tagging photographs. Most people who hesitate to share or tag photos on social media are probably just generally concerned about privacy; however, these photographs could be used for emotion analytics purposes via facial recognition. More radical, but less appealing, methods to avoid emotion analytics and other surveillance include "fashion adaptations" like garments and veils of specially woven cloth meant to obscure the wearer (Sedenberg \& Chuang, 2017, p. 11).

A more realistic strategy might encourage students not only to gain awareness of emotion's role and (mis)use in news and digital media, but also to examine companies' data policies and to evaluate potential governmental regulations that require ethical gathering and use of consumers' digital data. As Lapowsky (2018) describes, even some technology industry insiders are calling for more cautious use of digital platforms and user data, particularly with regard to both political content and the manipulation of users' attention and emotions. Some are suggesting for government regulation of digital publishing platforms and increased regulation to ensure users' data privacy, security, and control. One CEO even stated recently that the technology sector should be regulated just like the tobacco industry and other major industries (Hern, 2018). Additionally, some designers encourage the adoption of "exposure diversity" mechanisms that can be built into content recommendation or "feed" algorithms in order to promote more variety in the content seen by audiences (Helberger, Karppinen, \& D'Acunto, 2018). Students should be encouraged to monitor and cultivate their own perspectives on these developments as responsible technology users and participants in our increasingly technology-dependent economy and society. 


\section{REFERENCES}

Affectiva. (2018). Affectiva: Uses. Retrieved from https://www.affectiva.com/what/uses/

Algan, Y., Beasley, E., Vitaro, F., \& Tremblay, R. E. (2014). The impact of non-cognitive skills training on academic and non-academic trajectories: From childhood to early adulthood. European Research Council SOWELL Project, Sciences Po University. Retrieved from http://www .erc-sowell.com/en/research-articles/the-impact-of-non-cognitive-skillstraining-on-academic-and-non-academic-trajectories-from-childhood-to-early-adulthood-2/

Anderson, B. (2017, February 12). The rise of the weaponized AI propaganda machine. Retrieved from https://medium.com/join-scout/the-rise-of-the-weaponized-ai-propaganda-machine86dac61668b

Barbezat, D. P., \& Bush, M. (2013). Contemplative practices in higher education: Powerful methods to transform teaching and learning. San Francisco: Jossey-Bass.

Bodhi, B. (2013). What does mindfulness really mean? A canonical perspective. In J. M. G. Williams \& J. Kabat-Zinn (Eds.), Mindfulness: Diverse perspectives on its meaning, origins and applications (pp. 19-40). London: Routledge.

Brady, W. J., Wills, J. A., Jost, J. T., Tucker, J. A., \& Van Bavel, J. J. (2017). Emotion shapes the diffusion of moralized content in social networks. Proceedings of the National Academy of Sciences. Advance online publication. doi: 10.1073/pnas.1618923114

Caulfield, M. (2017, April 12). How 'news literacy' gets web misinformation wrong. Observer. Retrieved from http://observer.com/2017/04/how-news-literacy-gets-web-misinformationwrong-journalism-digital-media-fact-checking/

Checkology. (n.d.). Ten questions for fake news detection. Retrieved from http://www. thenewsliteracyproject.org/sites/default/files/GO-TenQuestionsForFakeNewsFINAL.pdf

Dehaene, S. (2014). Consciousness and the brain: Deciphering how the brain codes our thoughts. New York: Penguin.

El Kaliouby, R., Picard, R., \& Baron-Cohen, S. (2006). Affective computing and autism. Annals of the New York Academy of Sciences, 1093, 228-248. doi: 10.1196/annals.1382.016

Eyal, N. (2014). Hooked: How to build habit-forming products. New York: Penguin.

Felver, J. C, Celis-de Hoyos, C. E., Tezanos, K., \& Singh, N. N. (2016). A systematic review of mindfulness-based interventions for youth in school settings. Mindfulness, 7(1), 34-45. https://doi.org/10.1007/s12671-015-0389-4

Fleming, J. (2015). What do facts have to do with it? Exploring instructional emphasis in Stony Brook news literacy curriculum. Journal of Media Literacy Education, 7(3), 73-92.

Greenzeiger, M. F., Phulari, R., \& Sanghavi, M. K. (2015). U.S. Patent No. 8,965,828. Washington, D.C.: U.S. Patent and Trademark Office.

Helberger, N., Karppinen, K., \& D'Acunto, L. (2016). Exposure diversity as a design principle for recommender systems. Information, Communication, \& Society, 21(2), 191-207. doi: 10.1080/1369118X.2016.1271900

Heller, S. B., Shah, A. K., Guryan, J., Ludwig, J., Mullainathan, S., \& Pollack, H. A. (2017). Thinking, fast and slow? Some field experiments to reduce crime and dropout in Chicago. The Quarterly Journal of Economics, 132(1), 1-54. doi: 10.1093/qje/qjw033

Hern, A. (2018, January 24). Facebook should be 'regulated like cigarette industry,' says tech CEO. The Guardian. Retrieved from 
https://www.theguardian.com/technology/2018/jan/24/facebook-regulated-cigaretteindustry-salesforce-marc-benioff-social-media

Herndon, F. (2008). Testing mindfulness with perceptual and cognitive factors: External vs. internal encoding, and the cognitive failures questionnaire. Personality and Individual Differences, 44(1), 32-41. doi: 10.1016/j.paid.2007.07.002

Hsee, C. K. (1998). Less is better: When low-value options are valued more highly than high-value options. Journal of Behavioral Decision Making, 11(2), 107-121. https://doi.org/10.1002/(SICI)1099-0771(199806)11:2<107::AID-BDM292>3.0.CO;2-Y

Jones, K., Libert, K., \& Tynski, K. (2016). The emotional combinations that make stories go viral. Harvard Business Review. Retrieved from https://hbr.org/2016/05/research-the-linkbetween-feeling-in-control-and-viral-content

Kahneman, D. (2011). Thinking, fast and slow. New York: Farrar, Straus and Giroux.

Kleebpung, N. (2017). The challenge of media literacy education in Thailand. In B. S. De Abreu, P. Mihailidis, A. Y. L. Lee, J. Melki, \& J. McDougall (Eds.), International Handbook of Media Literacy Education (pp. 43-53). New York: Taylor \& Francis.

Klurfeld, J., \& Schneider, H. (2014). News literacy: Teaching the internet generation to make reliable information choices. Washington, DC: Center for Effective Public Management at Brookings. Retrieved from https://www.brookings.edu/wpcontent/uploads/2016/06/Klurfeld-SchneiderNews-Literacyupdated-7814.pdf

Lapowsky, I. (2018, February 8). Ethical tech will require a grassroots revolution. WIRED. Retrieved from https://www.wired.com/story/center-for-humane-technology-techaddiction/

Lee, D. (2017, December 18). Twitter's hate speech rules are expanded. BBC. Retrieved from http://www.bbc.com/news/technology-42376546

Maksl, A., Ashley, S., \& Craft, S. (2015). Measuring news media literacy. Journal of Media Literacy Education, 6(3), 29-45.

Malikhao, P. (2017). Culture and communication in Thailand. Singapore: Springer.

Marwick, A., \& Lewis, R. (2017). Media manipulation and disinformation online. Data \& Society Research Institute. Retrieved from https://datasociety.net/output/media-manipulation-anddisinfo-online/

McChesney, R. W. (2015). Rich media, poor democracy: Communication politics in dubious times. New York: The New Press.

Mosseri, A. (2018, January 11). News Feed FYI: Bringing people closer together. Retrieved from https://newsroom.fb.com/news/2018/01/news-feed-fyi-bringing-people-closer-together/

National Association for Media Literacy Education (NAMLE). (n.d.). Media literacy defined. Retrieved from https://namle.net/publications/media-literacy-definitions/

Nix, A. (2016, February 11). How big data got the better of Donald Trump. Retrieved from https://www.campaignlive.co.uk/article/big-data-better-donald-trump/1383209

Noone, C., Bunting, B., \& Hogan, M. J. (2016). Does mindfulness enhance critical thinking? Evidence for the mediating effects of executive functioning in the relationship between mindfulness and critical thinking. Frontiers in Psychology, 6. doi: 10.3389/fpsyg.2015.02043.

Notopoulos, K. (2018, February 15). How I cracked Facebook's new algorithm and tortured my friends. BuzzFeed News. Retrieved from https://www.buzzfeednews.com/article/katienotopoulos/how-i-cracked-facebooks-newalgorithm-and-tortured-my 
Pariser, E. (2011). The filter bubble: What the internet is hiding from you. New York: Penguin.

Parlapiano, A., \& Lee, J. C. (2018, February 2016). The propaganda tools used by Russians to influence the 2016 election. New York Times. Retrieved from https://www.nytimes.com/interactive/2018/02/16/us/politics/russia-propaganda-election2016.html

Perry, D. K., Burgess, M. H., Sowell, B. F., \& Gavin, K. A. (2017). Using competing narratives to increase critical thinking abilities. NACTA Journal, 61(1). Retrieved from Academic OneFile database.

Picard, R. (2000). Affective computing. Boston: MIT Press.

Potter, W. J. (2013). Media literacy (6th ed.). Los Angeles: Sage.

Reese, S. D. (2012). Global news literacy: Challenges for the educator. In P. Mihailidis (Ed.), News literacy: Global perspectives for the newsroom and the classroom (pp. 63-80). New York: Peter Lang.

Robertson, A. (2018, June 15). Trump's 2020 campaign is reportedly using former Cambridge Analytica employees to target voters. The Verge. Retrieved from https://www.theverge.com/2018/6/15/17468492/donald-trump-2020-data-propriacambridge-analytica-data-mining-campaign-report

Sedenberg, E., \& Chuang, J. (2017, September). Smile for the camera: privacy and policy implications of emotion AI. Paper presented at the TPRC45 conference, Washington, DC, September 2017. Retrieved from the arXiv database at https://arxiv.org/abs/1709.00396

Shearer, E., \& Gottfried, J. (2017, September 7). News use across social media platforms 2017. Pew Research Center. Retrieved from http://www.journalism.org/2017/09/07/news-useacross-social-media-platforms-2017/

Silverman, C. (2016, November 16). This analysis shows how viral fake election news stories outperformed real news on Facebook. BuzzFeed News. Retrieved from https://www.buzzfeed.com/craigsilverman/viral-fake-election-news-outperformed-realnews-on-facebook

Sivek, S. C. (2018a). New technologies of emotion and journalism ethics. Refereed research paper presented to the Ethics of Society and Ethics of Communication Working Group of the International Association for Media and Communication Research conference, Eugene, Oregon, June 20-24, 2018.

Sivek, S. C. (2018b). Ubiquitous emotion analytics and how we feel today. In M. S. Daubs \& V. R. Manzerolle (Eds.), Mobile and ubiquitous media: Critical and international perspectives (pp. 287-301). Digital Formations. New York: Peter Lang.

Slovic, P., Finucane, M. L., Peters, E., \& MacGregor, D. G. (2007). The affect heuristic. European Journal of Operational Research, 177, 1333-1352. doi: 10.1016/ j.ejor.2005.04.006

Society of Professional Journalists (SPJ). (2014). SPJ code of ethics. Retrieved from https://www.spj.org/ethicscode.asp

Spreeuwenberg, R. (2017, January 4). Does emotive computing belong in the classroom? EdSurge. Retrieved from https://www .edsurge.com/news/2017-01-04-does-emotive-computingbelong-in-the-classroom

Teper, R., Segal, Z. V., \& Inzlicht, M. (2013). Inside the mindful mind: How mindfulness enhances emotion regulation through improvements in executive control. Current Directions in Psychological Science, 22(6), 449-454. doi: 10.1177/0963721413495869 
Tiku, N. (2017, November 3). How Russia 'pushed our buttons' with fake online ads. WIRED. Retrieved from https://www.wired.com/story/how-russia-pushed-our-buttons-with-fakeonline-ads/

Tufekci, Z. (2015). Algorithmic harms beyond Facebook and Google: Emergent challenges of computational agency. Colorado Technology Law Journal, 13(2), 203-218.

Williamson, B. (2017). Moulding student emotions through computational psychology: Affective learning technologies and algorithmic governance. Educational Media International, 54(4), 267-288. doi: 10.1080/09523987.2017.1407080

Wolf, M., \& Gottwald, S. (2016). Tales of literacy for the 21st century. Oxford: Oxford University Press.

Yonck, R. (2017). Heart of the machine: Our future in a world of artificial emotional intelligence. New York: Arcade Publishing.

Zernike, K. (2016, February 29). Testing for joy and grit? Schools nationwide push to measure students' emotional skills. New York Times. Retrieved from https://www.nytimes.com/ 2016/03/01/us/testing-for-joy-and-grit-schools-nationwide-push-to-measure-studentsemotional-skills.html

Zomorodi, M. (2017). Bored and brilliant. New York: St. Martin's Press. 